\title{
Sexuality and behaviour of adolescents in relationship to sexually transmitted diseases in Libreville: a cross-sectional study
}

\author{
Nathalie L. Ambounda1, Sylvain H. Woromogo ${ }^{2 *}$, Felicite E. Yagata Moussa ${ }^{3}$, \\ Alain J. Kouanang', Vicky N. Simo Tekem ${ }^{4}$
}

\begin{abstract}
${ }^{1}$ Department of Gynecology Obstetrics, University Hospital Centre, Libreville, Gabon
${ }^{2}$ Department of Health Programme Management and Epidemiologic, Inter-States Centre for Higher Education in Public Health in Central Africa, Brazzaville, Republic of Congo

${ }^{3}$ Department of Public Health, Faculty of Health Sciences, University of Bangui

${ }^{4}$ Department of Public Health Faculty of Medicine and Health Sciences, University of Health Sciences, Libreville
\end{abstract}

Received: 19 April 2020

Accepted: 29 May 2020

\section{*Correspondence:}

Dr. Sylvain H. Woromogo,

E-mail: woromogos@gmail.com

Copyright: (C) the author(s), publisher and licensee Medip Academy. This is an open-access article distributed under the terms of the Creative Commons Attribution Non-Commercial License, which permits unrestricted non-commercial use, distribution, and reproduction in any medium, provided the original work is properly cited.

\begin{abstract}
Background: The World Health Organization (WHO) defines a sexually transmitted infection (STI) as an infection that is transmitted during unprotected sexual intercourse. Indeed, the highest rates of STIs are usually found among young people aged 15 to 24 . In Gabon, adolescents' knowledge of sexuality and STIs remains insufficient and early sexual intercourse is the most important factor favouring them. Improving adolescents' knowledge of sexuality education could influence their behaviour.

Methods: A cross-sectional study was conducted among 1256 adolescents in schools in Libreville. Their sociodemographic characteristics, knowledge about STIs, the description of their sexuality and their behaviour towards STIs were obtained through ratings and frequencies. Authos calculated the overall average of adolescents on their knowledge of STIs. Odds ration were used to establish the link between the different variables.

Results: Adolescents reported knowledge of STIs (1163/1256). AIDS was the most frequently cited STI by $94.50 \%$ of adolescents. Sexual intercourse was the main route of STI transmission and was cited by 687 adolescents who estimated that they knew at least one mode of STI transmission. Almost all female and male adolescents had poor knowledge of STIs, with $98.2 \%$ and $98.8 \%$ respectively. $84.96 \%$ of those with a sexual partner had ever had sex. More than half of sexually active adolescents had multiple partners.

Conclusions: Adolescents have a poor overall knowledge of STIs. Sexual risk behaviour remains very high, regardless of gender. To contain the scourge, awareness campaigns using all the means of communication at our disposal and especially the media.
\end{abstract}

Keywords: Adolescents, Behaviour, Sexuality, Sexually transmitted infections

\section{INTRODUCTION}

The World Health Organization (WHO) defines a sexually transmitted infection (STI) as an infection that is transmitted during unprotected sexual intercourse. These STIs are more common among adolescents and young adults. Indeed, the highest rates of STIs are usually found among young people aged 15 to 24 . Similarly, more than
$60 \%$ of new sexually transmitted infections and half of HIV infections are in this same age group. ${ }^{1}$ The STIs most commonly known to adolescents are HIV, syphilis, gonorrhoea and genital herpes., ${ }^{2,3}$ The others are often unknown. According to the WHO, adolescents' vulnerability to STIs is due to a lack of sexuality education, including STI prevention. ${ }^{1}$ In Gabon, adolescents' knowledge of sexuality and STIs remains 
insufficient and early sexual intercourse is the most important factor favouring them.,5 Improving adolescents' knowledge of sexuality education could influence their behaviour. It is important today to study their knowledge of adolescents on this subject. The primary objective is to study the behaviour of adolescents towards sexually transmitted infections. The secondary objectives were to describe the socio-demographic profile of adolescents, to present their knowledge on sexuality and sexually transmitted infections and to establish the relationship between their sexual behaviour and their socio-demographic characteristics.

\section{METHODS}

An analytical cross-sectional study was conducted in public and private secular schools in the communes of Libreville, Owendo and Akanda in Gabon from December 2015 to May 2016.

All adolescents aged 13-21 present in the classrooms or at the $5^{\text {th }}$ Pan-African summit of young leaders of the United Nations held in Libreville from 4 to 6 May 2016 at the Angondjé stadium located in the municipality of Akanda on the day of the study. Thus 1256 adolescents participated in this study. The sampling was exhaustive. The survey form was a structured and pre-tested questionnaire. More than 2000 questionnaires were distributed to targets who completed them anonymously.

\section{Variables and data analysis}

The variables were adolescents' socio-demographic characteristics, their knowledge about STIs, description of their sexuality and their behaviour towards STIs. Authors made a simple text entry on the word 2013 software and then transcribed on the CS pro software version 6.0. Adolescents' knowledge of STIs was rated as follows: all questions were rated on 1 point for a total score of 32 points. In the end, all the averages brought out of 20. Depending on the section concerned, adolescents with a score above 10/20 either had a good knowledge of STIs or those with a score below 10/20 had a poor knowledge. Authors established the relationship between knowledge of STIs on the one side and having an occasional sexual partner on the other side with certain variables by the ORs with their $95 \%$ confidence interval at the significance threshold $\mathrm{p}<0.005$. Data were analyzed on SPSS software version 20-32 bit which allowed us to calculate the average for each adolescent.

\section{Ethical considerations}

The study was only carried out after obtaining the approval of the Minister of Health of the National education, the ethics committee and the heads of schools on the one hand, and the chief of protocol at the $5^{\text {th }}$ panAfrican Summit of Young Leaders of the United Nations on the other hand. The survey form was only given to adolescents who had given their informed consent to participate in the study. The written consent included elements of informed consent as described in the legislation of the Ministry of Public Health and Population. The information was given in French in writing. It was worded in a way that was understandable so that all adolescents would sign it so that they could participate in the study.

\section{RESULTS}

Of the 2000 survey forms distributed, 1256 were returned, representing a response rate of $62.8 \%$.

Table 1: Socio-demographic characteristics of participants.

\begin{tabular}{|lcc|}
\hline Variables & $\begin{array}{l}\text { Number } \\
(\mathbf{N}=1,256)\end{array}$ & Percentage \\
\hline Age (years) & \multicolumn{2}{|c|}{} \\
\hline $13-18$ & 1023 & $81.45 \%$ \\
\hline $19-21$ & 233 & $18.55 \%$ \\
\hline Sex & & \\
\hline Male & 571 & $45.50 \%$ \\
\hline Female & 685 & $54.50 \%$ \\
\hline Socio-professional category 0 parents & (SPC) \\
\hline SPC 1 & 385 & $30.65 \%$ \\
\hline SPC 2 & 573 & $45.63 \%$ \\
\hline SPC 3 and SPC 4 & 298 & $23.72 \%$ \\
\hline Marital status of parents & & \\
\hline Bi-parental family & 548 & $43.60 \%$ \\
\hline Single-parent family & 708 & $56.40 \%$ \\
\hline School level & & \\
\hline $1^{\text {st }}$ cycle & \\
\hline $2^{\text {nd }}$ cycle & 946 & $24.68 \%$ \\
\hline
\end{tabular}

\section{Socio-demographic characteristics of participants}

These characteristics concerned the age, sex, educational level of participants and socio-economic level and marital status of parents (Table 1). The average age of school age adolescents was 16.69 years with extremes of 13 and 21 years. More than half were female $(54.5 \%)$. Adolescents from the middle category of parents (CSP2) were the most represented with a total of $573(45.63 \%)$.

Table 2: Distribution of adolescents on the knowledge of the different STIs.

\begin{tabular}{|lll|}
\hline $\begin{array}{l}\text { What STIs are you } \\
\text { aware of ? }\end{array}$ & $\begin{array}{l}\text { Number } \\
\text { AIDS }\end{array}$ & \begin{tabular}{l} 
Percentage \\
\hline Gonococcal disease
\end{tabular} \\
\hline Syphilis & 7899 & $94.50 \%$ \\
\hline Chlamydia & 726 & $67.50 \%$ \\
\hline Herpes & 601 & $62.42 \%$ \\
\hline HPV & 398 & $51.68 \%$ \\
\hline Hepatitis & 179 & $34.22 \%$ \\
\hline
\end{tabular}


Table 3: Factors associated with STIs' knowledge.

\begin{tabular}{|c|c|c|c|c|}
\hline Variables & Good knowledges & Poor knowledges & OR (CI 95\%) & $\mathbf{p}$ \\
\hline \multicolumn{5}{|l|}{ Age } \\
\hline $13-18$ & 5 & 1018 & - & \\
\hline $19-21$ & 10 & 223 & $9.13(3.09-26.97)$ & $<0.001$ \\
\hline \multicolumn{5}{|c|}{ Age of intercourse (years) } \\
\hline$<10$ & 3 & 1 & - & \\
\hline $10-15$ & 8 & 279 & $0.01(0.000-0.10)$ & $<0.001$ \\
\hline $16-21$ & 4 & 237 & $0.006(0.005-0.07)$ & $<0.001$ \\
\hline \multicolumn{5}{|l|}{ Sex } \\
\hline Male & 6 & 565 & $0.80(0.28-2.25)$ & 0.669 \\
\hline Female & 9 & 676 & - & \\
\hline \multicolumn{5}{|c|}{ SPC of parents } \\
\hline SPC 1 & 8 & 377 & $3.14(0.66-14.90)$ & 0.129 \\
\hline SPC 2 & 5 & 568 & $2.41(0.78-7.42)$ & 0.113 \\
\hline SPC 3 and 4 & 2 & 296 & - & \\
\hline \multicolumn{5}{|l|}{ School level } \\
\hline $1^{\text {st }}$ cycle & 5 & 941 & - & \\
\hline $2^{\text {nd }}$ cycle & 10 & 300 & $6.27(2.13-18.49)$ & $<0.001$ \\
\hline \multicolumn{5}{|c|}{ History of STIs } \\
\hline Yes & 9 & 74 & $8.98(3.11-25.97)$ & $<0.001$ \\
\hline No & 6 & 443 & - & \\
\hline \multicolumn{5}{|c|}{ Number of sexual partners } \\
\hline 1 & 3 & 107 & - & \\
\hline $2-5$ & 7 & 302 & $0.83(0.21-3.25)$ & 0.785 \\
\hline $5+$ & 5 & 108 & $1.65(0.39-7.08)$ & 0.495 \\
\hline
\end{tabular}

\section{Adolescents' knowledge of STIS}

Adolescents reported knowledge of STIs (1163/1256), or $96.60 \%$. Of these $711,61.13 \%$ reported being aware of STI transmission routes. AIDS was the most frequently cited STI by $94.50 \%$ of adolescents (Table 2). AIDS was the most frightening infection for adolescents and was cited 849 times by $73.01 \%$ of adolescents, followed by gonorrhoea $(6.70 \%)$, herpes $(5.24 \%)$, syphilis $(5.16 \%)$ and other STIs followed to a lesser extent. Clinical manifestations of STIs included testicular pain 224 times, or $19.26 \%$, leucorrhoea with $13.07 \%$, genital pruritus with $10.06 \%$, dyspareunia with $8.60 \%$ and urethral discharge with $4.90 \%$.

Sexual intercourse was the main route of STI transmission and was cited by 687 adolescents who estimated that they knew at least one route of STI transmission, which is $96.62 \%$. Infected objects were mentioned 277 times, representing $38.96 \%$, followed by blood transfusion with $19.55 \%$ and mother-to-child transmission with $13.92 \%$. Television was the main source of information. It was cited 532 times, or by $45.74 \%$ of adolescents. Then school classes with $39.55 \%$, talks with $11.55 \%$, radio with $4.90 \%$ and finally the health centre was mentioned with $7.39 \%$. In addition, 1241 adolescents (565 boys and 676 girls) have a poor knowledge of STIs (98.80\%). The overall average was 5.6 out of 20 , the majority of adolescents had a score of 6.87 out of 20. Factors associated with better knowledge of STIs were age between 19-21 years, age of first sexual intercourse, school level, and having a history of STIs (Table 3).

Table 4: Sexual behaviour of participants.

\begin{tabular}{|c|c|c|}
\hline Variables & Number & Percentage \\
\hline \multicolumn{3}{|c|}{ Do you have a sexual partner? } \\
\hline Yes & 532 & $42.36 \%$ \\
\hline No & 724 & $57.64 \%$ \\
\hline \multicolumn{3}{|c|}{ Have you ever had an occasional sexual partner? } \\
\hline Yes & 206 & $38.72 \%$ \\
\hline No & 326 & $61.28 \%$ \\
\hline \multicolumn{3}{|c|}{ Number of current sexual partners } \\
\hline 1 & 110 & $20.68 \%$ \\
\hline $2-4$ & 309 & $58.08 \%$ \\
\hline $5+$ & 113 & $21.24 \%$ \\
\hline \multicolumn{3}{|c|}{ History of STIs? } \\
\hline Yes & 83 & $15.60 \%$ \\
\hline No & 449 & $84.40 \%$ \\
\hline \multicolumn{3}{|c|}{ Age of first sexual intercourse (years) } \\
\hline$<10$ & 4 & $0.75 \%$ \\
\hline $10-15$ & 287 & $53.95 \%$ \\
\hline $16-21$ & 241 & $45.30 \%$ \\
\hline \multicolumn{3}{|c|}{$\begin{array}{l}\text { Do you use protection during regular sexual } \\
\text { intercourse? }\end{array}$} \\
\hline Always & 190 & $35.71 \%$ \\
\hline Sometimes & 262 & $49.25 \%$ \\
\hline Never & 80 & $15.04 \%$ \\
\hline
\end{tabular}




\begin{tabular}{|c|c|c|}
\hline Variables & Number & Percentage \\
\hline \multicolumn{3}{|c|}{$\begin{array}{l}\text { Do you protect yourself during occasional sexual } \\
\text { intercourse }(\mathbf{n}=\mathbf{2 0 6}) \text { ? }\end{array}$} \\
\hline Always & 123 & $59.71 \%$ \\
\hline Sometimes & 71 & $34.47 \%$ \\
\hline Never & 12 & $5.82 \%$ \\
\hline
\end{tabular}

\section{Sexual behaviour of participants}

Approximately half of the adolescents surveyed (532/1252) reported having a sexual partner and thus already having sexual relations. Of these, 206 (68.72\%) reported having an occasional sexual partner. Among those who reported having a regular sexual partner, 342
(64.29\%) sometimes admitted to protecting themselves or reported never using condoms, while 83 adolescents out of the $206(40.29 \%)$ who had had relations with an occasional sexual partner had not done so. Other sexual behaviours of adolescents are recorded in Table 4.

A number of factors are associated with having an occasional sexual partner. For example, girls are more exposed than boys to having an occasional sexual partner $(\mathrm{p}<0.001)$. The same holds for adolescents in $2^{\text {nd }}$ cycle. On the opposite, the age of first sexual intercourse and the socio-professional level of the parents are not associated with having an occasional sexual partner (Table 5).

Table 5: Factors associated with having an occasional sexual partner.

\begin{tabular}{|c|c|c|c|c|}
\hline \multirow{2}{*}{ Variables } & \multicolumn{2}{|c|}{ Occasional sexual partner } & \multirow{2}{*}{ OR (CI 95\%) } & \multirow[b]{2}{*}{ p value } \\
\hline & Yes & No & & \\
\hline \multicolumn{5}{|l|}{ Age (years) } \\
\hline $13-18$ & 89 & 70 & $2.78(1.89-4.07)$ & $<0.001$ \\
\hline $19-21$ & 117 & 256 & - & \\
\hline \multicolumn{5}{|c|}{ Age of intercourse (years) } \\
\hline$<10$ & 3 & 1 & $7.04(0.72-68.84)$ & 0.052 \\
\hline $10-15$ & 131 & 156 & $3.57(0.37-34.75)$ & 0.242 \\
\hline $16-21$ & 72 & 169 & - & \\
\hline \multicolumn{5}{|l|}{ Sex } \\
\hline Male & 87 & 199 & - & \\
\hline Female & 119 & 127 & $2.14(1.50-3.06)$ & $<0.001$ \\
\hline \multicolumn{5}{|c|}{ SPC of parents } \\
\hline SPC 1 & 99 & 140 & $0.93(0.61-1.43)$ & 0.756 \\
\hline SPC 2 & 48 & 108 & $0.59(0.36-0.95)$ & 0.029 \\
\hline SPC 3 and 4 & 59 & 78 & - & \\
\hline \multicolumn{5}{|l|}{ School level } \\
\hline $1^{\text {st }}$ cycle & 66 & 255 & - & \\
\hline $2^{\text {nd }}$ cycle & 140 & 71 & $7.61(5.14-11.29)$ & $<0.001$ \\
\hline \multicolumn{5}{|c|}{ History of STIs } \\
\hline Yes & 73 & 10 & $17.34(8.69-34.62)$ & $<0.001$ \\
\hline No & 133 & 316 & - & \\
\hline \multicolumn{5}{|c|}{ Number of sexual partners } \\
\hline 1 & 5 & 105 & - & \\
\hline $2-4$ & 152 & 157 & $20.33(8.07-51.24)$ & $<0.001$ \\
\hline $5+$ & 49 & 64 & $16.08(6.09-42.46)$ & $<0.001$ \\
\hline
\end{tabular}

\section{DISCUSSION}

This study was carried out in public and private schools in Libreville. The completion of the survey form was done the same day in the classrooms and privacy was not respected. This is a limitation to this study.

\section{Knowledge of STIS}

Only 15 adolescents out of 1256 surveyed have a good knowledge of STIs. Previous studies have addressed the same subject as authors have. Some results are different to ours, such as those of Mimbila-Mayi et al. ${ }^{5}$ This study results are similar to those of Grondin et al, in France in 2010, which showed boys and girls with poor knowledge of STIs by $24.8 \%$ and $15.0 \%$ respectively. ${ }^{3,5}$

This improvement is probably due to the regular sensibilisation undertaken in the media over the past several years. Also, authors did not use the same procedure for the determination of the score for good knowledge of STIs. Authors considered the knowledge of 
different STIs as well as the different transmission pathways.

This study results show that HIV infection is the most well-known among adolescents in Gabon, in decreasing order $94.5 \%$ or 1099 adolescents who knew about STIs cited it, followed by gonorrhoea $(67.50 \%)$ and syphilis $(62.42 \%)$. The same results were found in Gabon by Mimbila et al, and Grondin. In this study context, particular emphasis is placed on the AIDS pandemic through multiple media awareness campaigns and the mobilization of several NGOs; associated with the introduction of sex education in secondary school curricula.

Although knowledge about HIV infection appears to be good for the majority of adolescents, their knowledge about STI transmission routes is problematic because less than $62 \%$ of adolescents were able to identify at least one transmission route. Nevertheless, of the 711 adolescents who were able to identify at least one route of transmission, $96.62 \%$ had identified unprotected sex as their main route of transmission. These results are almost similar to those of Mimbila-Mayi et al. ${ }^{5}$

Television was the main source of information, cited 532 times, or $45.74 \%$ of adolescents who were familiar with STIs, as well as classroom courses (39.55\%). Similar results were found in Burkina Faso by Some et al, and Lerais in France. ${ }^{6,7}$ These results are justified by the fact that the subject of sexuality is still taboo in our countries. Thus, adolescents are forced to inform themselves through the media, which are the most widespread means of communication.

In total, 32 questions allowed us to assess adolescents' knowledge of STIs. The overall average of our series on this section was 5.6 out of 20 , the majority of adolescents had a score of 6.87 out of 20 . This leads us to conclude that Gabonese adolescents in school have a poor overall STI knowledge score, regardless of gender. These results are lower than those found in France by Grondin et al, where only $23 \%$ of adolescents had a poor STI knowledge score. Particular emphasis should be placed on sexual education for adolescents. Factors associated with a good knowledge of STIs were age, age of first sexual intercourse, education level and having a history of STIs. In this case, adolescents over the age of 18 years were more knowledgeable about STIs, probably because they had been in an environment where sex education was available. Adolescents who have had sex before the age of 10 are unlikely to have received advice from their parents at that age. Additionally, adolescents who have contracted an STI should be provided with preventive information during treatment.

\section{Sexual behaviour}

Almost half of authors workforce had a regular sexual partner at the time of the survey, $42.36 \%$, of whom the majority. The proportion of adolescents who have already had sexual intercourse appears to be higher than that reported by some authors, even if the environment is not the same..$^{3,8-13}$ The majority of sexually active adolescents, $53.95 \%$ had their first sexual intercourse between 10 and 15 years of age with a minimum age at first sexual intercourse of less than 10 years. These results are similar to those found in the Mimbila et al, study, where nearly half of the sample had already had their first sexual intercourse and the average age of first sexual intercourse: 15 years for boys and 13.6 years for girls. The results also remain different in France, according to the Grondin et al, study, where $33 \%$ of the adolescents studied reported having had their first sexual intercourse before the age of $15,64 \%$ between 15 and 18 , and nearly $3 \%$ after the age of 18 . Thus, authors can conclude that sexual intercourse remains very early in our country compared to others. Adolescent sexual health must be taken seriously by parents because it can affect the lives of adolescents. ${ }^{10}$ The consequences of a lack of sexual education are often dramatic; very often the result is unexpected pregnancies that can lead to death as a result of abortion. Only $64.6 \%$ of sexually active adolescents had used condoms during their first sexual intercourse. Study results are below those found by Godeau and Richter. ${ }^{14,15}$ In this case, authors did not ask about the reasons for condom use as was the case for Richter. The lack of awareness among adolescents, especially in school, about sexual health could explain this situation. Of the 532 adolescents who reported having a regular sexual partner, just under half, $38.7 \%$ reported having another occasional sexual partner. Only $59.7 \%$ of adolescents were still having safe sex with their casual sexual partners. And finally, 83 adolescents had a history of STIs. These results are also observed by Adohinzin in Bobo Dioulasso where this author found that sexual multi-partnership was practiced by $24 \%$ of young people, for several reasons. ${ }^{16}$ The low prevalence of STI history thus seems paradoxical in this study context where adolescents have acknowledged having several partners and with low use of protective measures. In view of these results, risk behaviours remain very high even if the consequence does not typically reflect this behaviour, these mixed results are probably related to difficulties in collecting intimate information in the field.

Factors associated with having a casual sexual partner were age, sex, grade level, STI history, parental socioprofessional level, and number of sexual partners. Adolescents under 18 tend to have casual sexual partners because of a lack of sex education.

And when there is a lack of sexual education, girls are much more vulnerable to having an occasional sexual partner in our society, especially if the parents have a medium or low socio-professional or economic level. Authors were unfortunately unable to consider certain factors that may be associated with having a casual sexual partner, such as religion, alcohol or drug use, as some authors have done. ${ }^{13,17}$ 


\section{CONCLUSION}

At the end of this study on 1256 adolescents attending school in the city of Libreville, Owendo and Akanda it appears that adolescents have a poor overall knowledge of STIs, that sexual risk behaviour remains very high and this regardless of gender. Authors believe that to contain the scourge, awareness campaigns using all the means of communication at our disposal and especially the media, remain our favourite weapon. School curricula should also emphasise sexuality education at different levels.

\section{ACKNOWLEDGMENTS}

Authors would like to thank the Ministry of Health of Gabon and the heads of schools in Libreville, Owendo and Akanda and also the NGO "Adolescence and Health " for their support.

Funding: No funding sources Conflict of interest: None declared

Ethical approval: The study was approved by the Institutional Ethics Committee

\section{REFERENCES}

1. Dehne KL, Riedner G. Sexually transmitted infections amoung adolescents: the need for adequate health services. WHO, Geneva; 2004.

2. HIV and STI prevention among young people. CRIPS Provence-Alpes-Côte d'Azur, 2015. Bulletin Officiel du Ministère de l'Education nationale, 2010. Available at: http: //www.paca.lecrips.net. Accessed on $12^{\text {th }}$ March 2020.

3. Grondin C, Duron S, Robin F, Verret C, Imbert P. Adolescents' knowledge and behavior on sexuality, infectious transmitted diseases, and humain papillomavirus vaccination: results of a survey in a French high school. Arch Pediatr. 2013;20(8):84552.

4. Vierin Nzame Y, Mimbila Mayi M, Essomeyo P, Moussavou A. Sexually transmitted infections in schooled adolescents in Libreville. Arch Pediatr. 2013;20(5):562-3.

5. Mimbila-Mayi M, Nzame Vierin Y, Biloghe AS, Moussavou A. Knowledge and behaviour of adolescents in sexual health in Gabon. Clin Mother Child Health. 2011;8(1):3.

6. Some DT, Some DA, Hien H, Diallo R, Zingue D, Diallo I, et al. Sexual and reproductive health of adolescent girls in Bobo Dioulasso, Burkina Faso: the role of parent-adolescent communication for risk reduction. Pan Afr Med J. 2012;11:65.
7. Lerais I, Durant ML, Gardella F, Hofliger P, Pradier C, Giordanengo V, et al. Survey on the knowledge, opinions and behaviour of high school students around human papilloma virus (HPV), France, Alpes-Maritimes, 2009. BEH. 2010;11:97-100.

8. Cissé CT. Study of adolescents' knowledge, attitudes and practices in schools on sexually transmitted infections (STIs) in the Commune of Bamako District. 2013. Available at: http://www.keneya.net/fmpos/theses/2013/med/pdf/1 3M55.pdf. Accessed on $15^{\text {th }}$ March 2020.

9. Foumane P, Chiabi A, Kamdem C, Monebenimp F, Sama Dohbit J, Enow Mbu R. Sexual activity of adolescent school girls in an urban secondary school in Cameroon. J Reprod Infertil. 2013;14(2):85-9.

10. Glasier A, Gülmezoglu AM, Schmid GP, Moreno CG, Van Look PF. Sexual and reproductive health: a matter of life and death. Lancet. 2006;368:1595-607.

11. Valois RF, Oeltmann JE, Waller J, Hussey JR. Relationship between number of sexual intercourse partners and selected health risk behaviors among public high school adolescents. J Adolesc Health. 1999;25(5):328-35.

12. Lema VM, Hassan MA. Knowledge of sexually transmitted diseases, HIV infection and AIDS among sexually active adolescents in Nairobi, Kenya and its relationship to their sexual behaviour and contraception. East Afr Med J. 1994;71(2):122-8.

13. Minet TH, Jing M, Guilan G, Berhe TH, Eyasu HT. Predictors of high HIV/AIDS risk sexual behaviors: comparison study among Cameroonian and Gabonese youthaAged 15-24 years. J HIV Retrovirus. 2017;3(1):1-11.

14. Godeau E, Gabhainn SN, Vignes C, Ross J, Boyce W, Todd J. Contraceptive use by 15 -years-old students at their last sexual intercourse. Arch Pediatr Adolesc Med. 2008;162(1):66-73.

15. Richter DL, Valois RF, McKeown RE, Vincent ML. Correlates of condom use and number of sexual partners among high school adolescents. J Sch Health. 1993;63(2):91-6.

16. Adohinzin CC, Meda N, Belem AM, Ouédraogo GA, Sombie I, Berthe A, et al. Risk assessment in young people living in Bobo Dioulasso: analysis of factors associated with sexual precocity and multiple partners. Pan Afr Med J. 2016;25:132.

17. Berg CJ, Lowe K, Stratton E, Goodwin SB, Grimsley L, Rodd J, et al. Sociodemographic, psychosocial and health behavior risk factors associated with sexual risk behaviors amoung Southeastern US college students. Open J Prev Med. 2014;4(1):387-95.

Cite this article as: Ambounda LN, Woromogo SH, Yagata-Moussa FE, Kouanang AJ, Simo Tekem VN. Sexuality and behaviour of adolescents in relationship to sexually transmitted diseases in Libreville: a cross-sectional study. Int J Reprod Contracept Obstet Gynecol 2020;9:2782-7. 